\title{
Stochastic Modeling for Coliform Count Assessment in Ground Water
}

\author{
A. Udaya*, M. Kumaran and P.V.Pushpaja \\ Department of Statistics, \\ Nehru Arts and Science College, Kanhangad, \\ Kasaragod, Kerala, India \\ First supporter of the project, Email: udayastat@gmail.com
}

\begin{abstract}
Stochastic models are derived to estimate the level of coliform count in terms of MPN index, one of the most important water quality characteristic in ground water based on a set of water source location and soil characteristics. The study is based on about twenty location and soil characteristics, majority of them are observed through laboratory analysis of soil and water samples collected from nearly thee hundred locations of drinking water sources, wells and bore wells selected at random from the district of Kasaragod. The water contamination in wells are found to be relatively more as compared to bore wells. The study reveals that only $7 \%$ of the wells and $40 \%$ of the bore wells of the district are within the permissible limit of WHO standard of drinking water quality. The level of contamination is very high in the hospital premises and is very low in the forest area. Two separate multiple ordinal logistic regression models are developed to predict the level of coliform count, one for well and the other for bore well. The significant feature of this study is that in addition to scientifically proving the dependence of the water quality on the distances from waste disposal area and septic tanks etc., it highlights the dependence of two other very significant soil characteristics, the soil organic carbon and soil porosity. The models enable to predict the quality of water in a location based on the set of soil and location characteristics. One of the important uses of the model is in fixing safe locations for waste dump area, septic tank, digging well etc. in town planning, designing residential layouts, industrial layouts, hospital/hostel construction etc. This is the first ever study to describe the ground water quality in terms of the location and soil characteristics.
\end{abstract}

Key words: Generalized linear model, Logistic regression model, Ordinal logistic regression model, Coliform count, MPN index, Prediction, Stochastic model, Water quality.

\section{Introduction}

The quality of water is described in terms of about a dozen characteristics identifiable by means of lab tests of water samples. Quality of water is described in three categories microbial, physical and chemical. The microbial characteristics include E. coli and coliform organisms, physical characteristics include temperature, smell, taste, colour and turbidity and chemical characteristics include $p H$, total dissolved solids (TDS), total hardness (TH), chlorides (Cl), sulphates $\left(\mathrm{SO}_{4}\right)$, fluorides $(\mathrm{F})$, nitrates $\left(\mathrm{NO}_{3}\right)$, calcium $(\mathrm{Ca})$, magnesium $(\mathrm{Mg})$, iron $(\mathrm{Fe})$, etc. Microbiological contamination in drinking water due to the presence of Escherichia coli (E. coli) and coliform organisms is more severe than physical and chemical contaminations because of the risk of 
immediately affected severe health issues.

All most all the studies on water quality reported so far are confined to the inter relationships among the water quality characteristics and a few are on the relationship between the environmental effects, seasonal changes, land use and water quality using multivariate statistical techniques like principal component analysis, factor analysis, discriminant analysis and multiple regression models.

Survey of literature indicates that only very limited scientific studies were done so far for the prediction of water quality using advanced stochastic models based on location and soil characteristics. Some of the studies, based on the interrelations among the various water quality characteristics, reported at the national level are Khurana et al. [2009] [1], Ramakrishnaiah et al. [2009] [2], Kumar et al. [2010] [3], Kumar and Sinha [2010] [4], Kumar and Singh [2010] [5], Bandela et al.[2014] [6] etc. Water quality studies reported in Kerala are Karthick et al. [2012] [7] and Behera et al. [2012] [8].

At the international level the major studies reported are Loucks et al. [2005] [9], Mannina et al. [2009] [10], Pathak et al. [2012] [11] and Mustapha et al. [2012] [12]. Fannin et al. [1985] [13] conducted a study to fit a multiple regression model for evaluating non-point source contributions to water quality in the Green River, Wyoming. They developed model for predicting water quality characteristics like phosphorus, nitrate, and dissolved solids using explanatory variables like geologic substrate, land use, channel slope, etc. The explanatory variables for each water quality model were identified using simple correlation matrix. Hynds et al. [2012] [14] developed a model to predict microbial contamination using local meteorological data and they found that local bedrock type, local subsoil type, groundwater vulnerability, septic tank setback distance, and 48 hours antecedent precipitation were all significantly associated with thermotolerant coliform (TTC) presence. Heydari et al. [2013] [15] reported study of correlation matrices among water quality characteristics. Bain et al. [2014] [16] conducted a study to estimate the effect of microbial contamination in different water source types including piped water supply and developed water quality models for different water source types using principal component analysis.

It is clear that water pollution due to microbial contamination is mainly because of lack of scientific management of industrial and domestic wastes, increased use of pesticides and chemical fertilizers in agriculture, poor sanitation facilities etc. Many factors can affect the quality of the water in an ecosystem including discharges of industrial and agricultural wastes, domestic and institutional wastes, contamination from leakages from septic tanks, proximity to garbage disposal sites etc. Field observations and soil testing allow us to assess the links between land use and its effects on water quality. Thus there is sufficient reason to suspect strong correlation between soil structure and water quality characteristics. Survey of literature indicates that no scientific study were done so far for the estimation of coliform count in ground water based on location and soil characteristics at national or international levels. In this study our objective is to measure the correlation of the water quality characteristic coliform count with several soil and water source location characteristics and exploit the same to estimate the level of coliform count in ground water that would be available in a location.

This study is conducted in the district of Kasaragod of Kerala State. Data has been collected by the method of stratified random sampling by regarding the land of the district divided into 6 strata namely Coastal area, Forest area, Hospital premises, Market places, Pesticide using area and Waste dump area depending on the levels of contamination of ground water. Since well and bore well water sources are the main sources of drinking water in the district, we confined our study on well and bore well water sources. As many as 300 water 
sources were selected at random ranging 50 to 60 from the neighborhood of each stratum. Soil and water samples were collected from these locations. The location characteristics observed are distance of water source from septic tank, slope of water source from septic tank, number of septic tanks near to the water source, distance of water source from nearest stratum boundary, slope of water source from nearest stratum boundary and depth of the water source. The soil characteristics measured are porosity, $\mathrm{pH}$, electrical conductivity, organic carbon, texture, iron, sulphur, phosphorus, calcium, magnesium, copper, zinc, manganese and potassium. All these characteristics combined together we call as water source location characteristics. Coliform counts in water and soil characteristics are identified by testing water and soil samples in the laboratory of Kerala Agricultural University Campus at Padannakkad. Coliform count in water is identified using Most Probable Number (MPN) method with 3 tube test procedure.

In this article we describe the procedure of estimating coliform count in ground water using ordinal multiple logistic regression model. The model utilizes effectively the benefit of the relationship of coliform count with water source location characteristics. The whole analyzes were done using SPSS.

The remaining part of this article is organized as follows: section 2 describes briefly some of the advanced statistical concepts based on which the study is made. Basic statistical characteristics of the data under study are presented in the first sub section of section 3 and the model building process for well and bore well and their features and applications are discussed in the next sub sections. The article closes with a conclusion, acknowledgment and the list of references.

\section{Statistical Background}

Following the terminology and convention in general linear modeling we regard the coliform count MPN/100ml in ground water as the response variable and water source location characteristics as the explanatory variables. Constructing the correlation matrix between the response variable and set of explanatory variables we identified the highly correlated water source location characteristics. As per the international standard the MPN Index is categorized into 22 ordinal categories as $0,3,4,7,9,10,14,15,20,21,23,28,39$, $43,75,120,150,210,240,460,1100$ and 2400 . Since the response variable is ordinal with 22 categories and explanatory variables are 20 in number an ordinal multiple logistic regression model is appropriate.

A multiple regression model is a model belonging to the class of general linear models. The generalized linear model (GLM) is a flexible generalization of general linear regression model when the response variable has non normal error distribution. Logistic regression model is a special case of GLM where the response variable has a binomial or multinomial distribution. Ordinal logistic regression model is an extension of the general logistic regression model to the case of ordinal categorical response. The key assumption in ordinal regression

is that the effects of any explanatory variables are consistent or proportional across the different categories, which is usually termed as the assumption of proportional odds (assumption of parallel lines). A detailed description of the model choice, fitting and the various features of the models are available in standard text books such as Yule and Kendall [1922] [17], Koutsoyiannis [1973] [18], Draper and Smith [1998] [19], Hosmer and Lemeshow [2000] [20], Kleinbaum and Klein [2002] [21], Montgomery, Peck and Vining [2003] [22].

In this study we use the proportional odds (cumulative logit) ordinal logistic model. The model involves an outcome $\mathrm{D}$ with $\mathrm{j}$ ordered categories and $\mathrm{p}$ explanatory variables $x_{1}, x_{2}, \ldots, x_{p}$ and the probability that an outcome is in any of the categories greater than or equal to $\mathrm{k}$ is given by a logistic function as, 


$$
\begin{gathered}
\operatorname{Prob}(D \geq k)=\frac{1}{1+e^{-\left(\alpha_{k}+\beta_{1} x_{1}+\beta_{2} x_{2}+\ldots+\beta_{p} x_{p}\right)}} ; \\
k=1,2,3, \ldots, j-1, \\
\operatorname{Prob}(D=k)=\operatorname{prob}(D \geq k)-\operatorname{prob}(D \geq k+1) .
\end{gathered}
$$

and the odds ratio is given by,

$$
\text { Odds Ratio }=\frac{\operatorname{prob}(D \geq k)}{\operatorname{prob}(D<k)}=e^{\left(\alpha_{k}+\beta_{1} x_{1}+\beta_{2} x_{2}+\ldots+\beta_{p} x_{p}\right)}
$$

where $\alpha_{k}$ is the intercept corresponding to $k^{\text {th }}$ category and $\beta_{1}, \beta_{2}, \ldots, \beta_{p}$ are the regression coefficients corresponding to the explanatory variables. As per the assumption of proportional odds the regression coefficients are same for each value of $\mathrm{k}$. The first category does not have an odds associated with it since as per equation (3) odds ratio cannot exist for $\mathrm{k}=1$.

An alternate model formulation for proportional odds ordinal logistic regression model is,

$$
\begin{gathered}
\operatorname{prob}(D \leq k)=\frac{1}{1+e^{-\left(\alpha_{k}-\left(\beta_{1} x_{1}+\beta_{2} x_{2}+\ldots+\beta_{p} x_{p}\right)\right)}} ; \\
k=1,2,3, \ldots, j-1, \\
\operatorname{prob}(D=k)=\operatorname{prob}(D \leq k)-\operatorname{prob}(D \leq k-1) ; \\
k \neq 1 .
\end{gathered}
$$

and

$$
\operatorname{prob}(D=1)=\operatorname{prob}(D \leq 1)
$$

and the odds ratio in this case is,

$$
\begin{aligned}
& \text { Odds Ratio }=\frac{\operatorname{prob}(D \leq k)}{\operatorname{prob}(D>k)} \\
& =e^{\left(\alpha_{k}-\left(\beta_{1} x_{1}+\beta_{2} x_{2}+\ldots+\beta_{p} x_{p}\right)\right)}
\end{aligned}
$$

In this formulation odds ratio does not exist for the last category.

SPSS provides results based on the alternate formulae (4) to (7) for proportional odds ordinal logistic regression model. The outcome with highest probability is considered as the expected category in which the event is happening.

For the validity of the multiple ordinal logistic regression model the variables in the model must satisfy the assumption of proportional odds.

\section{Parameter Estimation in Ordinal Logistic Regression Model}

The method of maximum likelihood is the theoretical basis for parameter estimation in ordinal logistic 
regression model. The log likelihood function in ordinal logistic regression model in equation (4) is

$$
\left.\ln L(Y, B)=\sum_{i=1}^{j-1}\left[r_{i} \varphi_{i}-r_{i+1} v_{i}\right)\right]
$$

where

$$
\begin{aligned}
& r_{i}=\sum_{k=1}^{i} n k, \mathrm{n} \text { is the total number of observations (total cases). } \\
& \varphi_{i}=\log \left(\frac{Y_{i}}{Y_{i+1}-Y_{i}}\right), Y_{i}=\operatorname{prob}(D \leq i) \\
& v_{i}=\log \left(\frac{Y_{i+1}}{Y_{i+1}-Y_{i}}\right), i=1,2, \ldots, j-1 \\
& Y=\left[Y_{1}, Y_{2}, \ldots, Y_{j}\right]^{T}, Y_{j}=1
\end{aligned}
$$

and $B=\left[\alpha_{1}, \alpha_{2}, \ldots, \alpha_{j-1}, \beta_{1}, \beta_{2}, \ldots, \beta_{p}\right]^{T}$

The set of equations obtained by equating to zero the first order derivatives of (8) with respect to each component of B, usually known as the likelihood equations, solving which we can estimate the parameters. Though Fisher's method of scoring (Newton-Raphson iterative estimation method) can be used for parameter estimation, the actual implementation of maximum likelihood results in an algorithm based on iteratively re-weighted least squares (IRLS). The iterative procedure is repeated until change in the successive estimates is less than the tolerance level.

In fitting the above model one important issue is selecting the explanatory variables for inclusion in the model. Normally all those explanatory variables that are highly correlated with the response variable are to be included. However, due to joint effects, the variables having significant influence in the model need be selected judiciously. There are several statistical procedures for selecting variables for inclusion in the model such as stepwise regression, forward selection, backward elimination etc. Adequacy of the fitted model is assessed using Pearson and deviance measures based on chi-square statistics and the coefficient of determination Pseudo $\mathrm{R}^{2}$ (higher the value of Pseudo $\mathrm{R}^{2}$ more appropriate the fitted model). The significance of each regression coefficient can also be tested using Wald statistics. Even after fitting the model as described above there are several techniques to verify the model adequacy as well as the extent to which the model assumptions are satisfied (post-hoc tests). Finally the model adequacy can be validated using about $10 \%$ of the real data. Further details on estimates and their properties can be had from the standard references [17], [18], [19], [20], [21], [22].

\section{Results and Discussion}

\section{Preliminary Analysis}

The basic characteristics of the study variables are presented in Table (1) and Table (2). Since the response variable is ordinal with 22 categories, arithmetic mean does not provide the good measure of average. Instead of arithmetic mean, mean rank of the values provide a better measure of central tendency. Thus the average coliform count in this study is the coliform count corresponding to the average rank of the coliform count values. The MPN index of the water samples range from 0 to 2400 , while the average level of contamination is 
much more in wells as compared to bore wells. As Table (2) reveals out of the 20 observed water source location characteristics the levels of soil potassium, manganese, iron, calcium and magnesium are highly heterogeneous over the area.

Table 1

Descriptive Statistics of Coliform Count (MPN Index)

\begin{tabular}{llll}
\hline Descriptives & Overall & Well & Bore Well \\
\hline Average & 21 & 39 & 10 \\
$95 \%$ Confidence Interval & $(15,23)$ & $(21,43)$ & $(7,14)$ \\
Variance & 65.96 & 60.89 & 44.00 \\
Minimum & 0 & 0 & 0 \\
Maximum & 2400 & 2400 & 2400 \\
Skewness & 0.42 & -0.11 & 1.51 \\
Kurtosis & -1.34 & -1.33 & 0.95 \\
\hline
\end{tabular}

Table 2

Descriptive Statistics of Soil and Location Characteristics

\begin{tabular}{|c|c|c|c|c|}
\hline Variable & Minimum & Maximum & Mean & Variance \\
\hline Distance of water source from nearest stratum boundary in meter & 0.50 & 500.00 & 137.15 & 19802.63 \\
\hline Slope of water source from stratum angle in degrees & -86.50 & 63.40 & 3.85 & 519.30 \\
\hline Depth of water source in meters & 4.00 & 80.00 & 26.01 & 453.98 \\
\hline Distance from nearest septic tank in meters & 5.00 & 110.00 & 14.94 & 78.17 \\
\hline Slope from nearest Septic tank in degrees & -29.50 & 46.80 & 2.65 & 80.93 \\
\hline Number of septic tanks near to the water source & 1.00 & 10.00 & 2.00 & 5.10 \\
\hline Distance from nearest flowing water body & 3.00 & 4000.00 & 1048.23 & 1546569.12 \\
\hline Soil $\mathrm{pH}$ & 3.08 & 7.56 & 5.98 & 0.63 \\
\hline Soil EC in micro Siemens & 0.50 & 155.00 & 14.80 & 200.59 \\
\hline Soil organic carbon in $\%$ & 0.05 & 5.81 & 2.13 & 2.60 \\
\hline Soil Potassium in kg/ha & 31.36 & 1736.00 & 223.75 & 30103.48 \\
\hline Soil Sulphur in $\mathrm{kg} / \mathrm{ha}$ & 0.00 & 43.45 & 2.73 & 47.40 \\
\hline Soil Phosphorus in $\mathrm{kg} / \mathrm{ha}$ & 0.00 & 159.60 & 28.28 & 1255.54 \\
\hline Soil Porosity in $\%$ & 20.00 & 61.55 & 37.23 & 88.26 \\
\hline Soil Manganese in $\mathrm{kg} / \mathrm{ha}$ & 0.00 & 443.52 & 39.23 & 3072.96 \\
\hline Soil Zinc in $\mathrm{kg} / \mathrm{ha}$ & 0.00 & 250.88 & 29.05 & 980.13 \\
\hline Soil Copper in $\mathrm{kg} / \mathrm{ha}$ & 0.00 & 99.68 & 13.27 & 173.30 \\
\hline Soil Iron in $\mathrm{kg} / \mathrm{ha}$ & 8.00 & 611.52 & 125.95 & 10180.74 \\
\hline Soil Calcium in $\mathrm{kg} / \mathrm{ha}$ & 25.76 & 27720.00 & 3505.26 & 14271539.65 \\
\hline Soil Magnesium in $\mathrm{kg} / \mathrm{ha}$ & 28.46 & 228.78 & 107.16 & 1274.96 \\
\hline
\end{tabular}

Technically pure drinking water must be free of any coliform organisms. As per WHO standards coliform organisms should not be detectable in drinking water (MPN index should be 0). Table (3) gives the distribution of coliform count in well and bore well water sources. This leads to the conclusion that only $7 \%$ of the well water sources and $40 \%$ of the bore well water sources in the study area are within the permissible limit of WHO standard of drinking water quality. This indicates that about $93 \%$ of the well water sources and nearly $60 \%$ of bore well water sources in study area are contaminated. 
Table 3

Frequency Table of Coliform Count (MPN Index)

\begin{tabular}{|c|c|c|c|c|c|c|}
\hline \multirow{2}{*}{$\begin{array}{l}\text { Coliform } \\
\text { Count }\end{array}$} & \multicolumn{2}{|c|}{ Overall } & \multicolumn{2}{|c|}{ Well } & \multicolumn{2}{|c|}{ Bore Well } \\
\hline & Frequency $(\%)$ & $\begin{array}{l}\text { Cumulative } \\
\text { Frequency (\%) }\end{array}$ & Frequency $(\%)$ & $\begin{array}{l}\text { Cumulative } \\
\text { Frequency (\%) }\end{array}$ & Frequency $(\%)$ & $\begin{array}{l}\text { Cumulative } \\
\text { Frequency (\%) }\end{array}$ \\
\hline 0 & 20.67 & 20.67 & 6.59 & 6.59 & 40.48 & 40.48 \\
\hline 3 & 9.67 & 30.33 & 8.98 & 15.57 & 11.11 & 51.59 \\
\hline 4 & 8.00 & 38.33 & 4.19 & 19.76 & 12.70 & 64.29 \\
\hline 7 & 7.00 & 45.33 & 6.59 & 26.35 & 7.14 & 71.43 \\
\hline 9 & 1.33 & 46.67 & 0.00 & 26.35 & 3.17 & 74.60 \\
\hline 10 & 1.33 & 48.00 & 2.40 & 28.74 & 0.00 & 74.60 \\
\hline 14 & 0.33 & 48.33 & 1.20 & 29.94 & 0.79 & 75.40 \\
\hline 15 & 1.33 & 49.67 & 2.99 & 32.93 & 1.59 & 76.98 \\
\hline 20 & 1.67 & 51.33 & 12.57 & 45.51 & 0.00 & 76.98 \\
\hline 21 & 9.67 & 61.00 & 4.79 & 50.30 & 5.56 & 82.54 \\
\hline 23 & 3.67 & 64.67 & 1.20 & 51.50 & 2.38 & 84.92 \\
\hline 28 & 0.67 & 65.33 & 0.60 & 52.10 & 0.00 & 84.92 \\
\hline 39 & 0.33 & 65.67 & 2.99 & 55.09 & 0.00 & 84.92 \\
\hline 43 & 2.00 & 67.67 & 0.00 & 55.09 & 0.79 & 85.71 \\
\hline 75 & 7.67 & 75.33 & 10.78 & 65.87 & 3.17 & 88.89 \\
\hline 120 & 2.67 & 78.00 & 4.19 & 70.06 & 0.79 & 89.68 \\
\hline 150 & 0.67 & 78.67 & 0.60 & 70.66 & 0.79 & 90.48 \\
\hline 210 & 0.67 & 79.33 & 1.20 & 71.86 & 0.00 & 90.48 \\
\hline 240 & 4.00 & 83.33 & 5.39 & 77.25 & 1.59 & 92.06 \\
\hline 460 & 5.33 & 88.67 & 5.39 & 82.63 & 5.56 & 97.62 \\
\hline 1100 & 4.00 & 92.67 & 6.59 & 89.22 & 0.79 & 98.41 \\
\hline 2400 & 7.33 & 100 & 10.78 & 100 & 1.59 & 100 \\
\hline
\end{tabular}

Figure (1) presents stratum wise comparison of level of coliform count. The average level of coliform count in the case of bore wells remain more or less very low as compared to those of wells. The average level of contamination of wells is the highest in the hospital area and the lowest in the forest area.

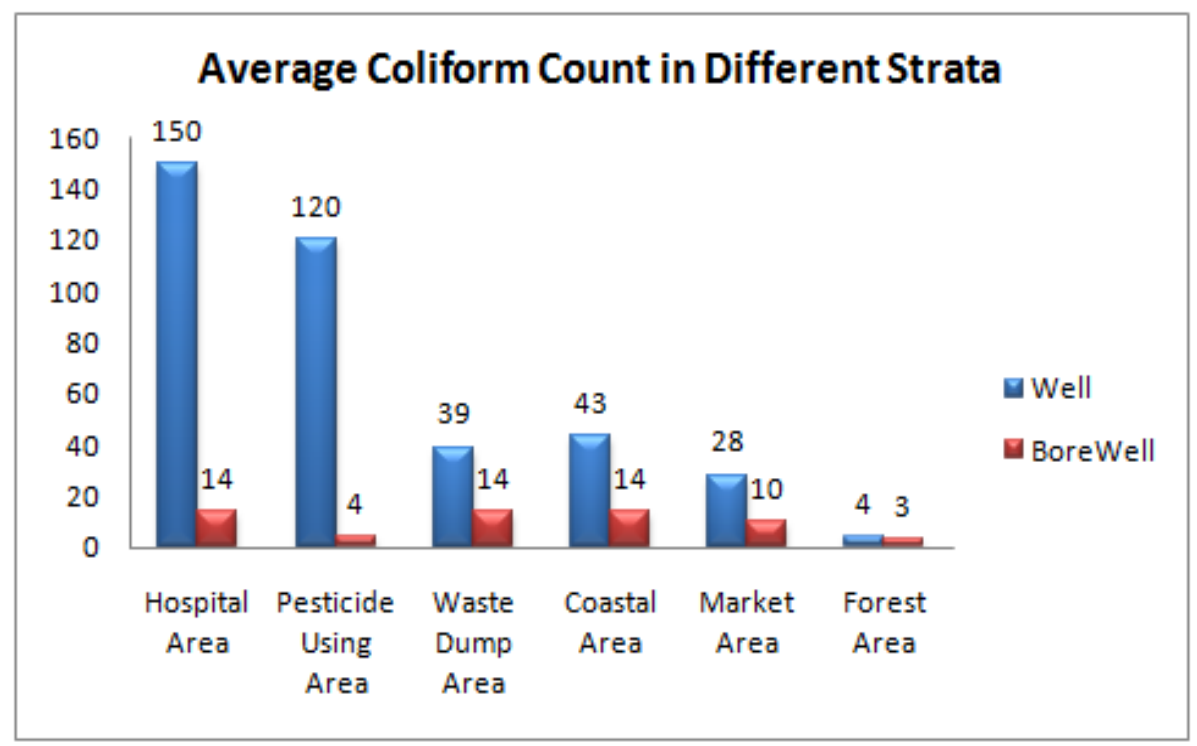

Figure 1. Comparison of Mean Coliform Count in Various Locations. 
Average Coliform Count Comparison Over Well and Bore Well. Next we shall compare the level of coliform count between wells and bore wells. Since the coliform count data is ordinal we used Mann-Whitney $\mathrm{U}$ test for the comparison.

Null Hypothesis, $H_{0}$ : Average coliform count is equal for wells and bore wells

Alternate Hypothesis, $H_{1}$ : Average coliform count is higher for well water.

Table (4) gives the test results. Since P-Value of the test is $<0.05$ we reject the null hypothesis and conclude that the average of coliform count in wells and bore wells are significantly different.

Table 4

Mann-Whitney U test for Equality of Average MPN Levels Over Wells and Bore wells

\begin{tabular}{ll}
\hline Mann-Whitney U & P-Value \\
\hline 4746 & 0.00 \\
\hline
\end{tabular}

We describe below the advanced model based analysis.

\section{Model Based Analysis}

Table 5

Correlation Matrix

\begin{tabular}{|c|c|c|c|}
\hline \multirow{2}{*}{ Explanatory Variables } & \multicolumn{3}{|c|}{ Response Variable Y } \\
\hline & Overall & Well & Bore Well \\
\hline Distance of water source from nearest stratum boundary in meters $\left(X_{1}\right)$ & $-0.307^{* *}$ & $-0.334^{* *}$ & $-0.231^{*}$ \\
\hline Slope from nearest stratum boundary angle in degrees $\left(X_{2}\right)$ & -0.056 & -0.110 & -0.059 \\
\hline Depth of water source in meters $\left(X_{3}\right)$ & $-0.199^{* *}$ & 0.096 & -0.034 \\
\hline Distance from nearest septic tank in meters $\left(X_{4}\right)$ & $-0.022^{* *}$ & $-0.172^{* *}$ & $-0.145^{* *}$ \\
\hline Slope from nearest septic tank in degrees $\left(X_{5}\right)$ & $0.383^{* *}$ & $0.442^{* *}$ & -0.011 \\
\hline Number of septic tanks near to the water source $\left(X_{6}\right)$ & $0.544^{* *}$ & $0.719^{* *}$ & $0.496^{* *}$ \\
\hline Distance from nearest flowing water body in meters $\left(X_{7}\right)$ & $0.142^{*}$ & $0.253^{* *}$ & 0.118 \\
\hline Soil pH $\left(X_{8}\right)$ & $-0.142^{*}$ & -0.155 & 0.179 \\
\hline Soil EC in micro Siemens $\left(X_{9}\right)$ & 0.029 & 0.130 & -0.031 \\
\hline Soil Organic Carbon in $\%\left(X_{10}\right)$ & $0.635^{* *}$ & $0.637^{* *}$ & $0.533^{* *}$ \\
\hline Soil Potassium in $\mathrm{kg} / \mathrm{ha}\left(X_{11}\right)$ & $0.188^{* *}$ & $0.217^{* *}$ & 0.020 \\
\hline Soil Sulphur in $\mathrm{kg} / \mathrm{ha}\left(X_{12}\right)$ & $0.323^{* *}$ & $0.502^{* *}$ & 0.032 \\
\hline Soil Phosphorus in $\mathrm{kg} / \mathrm{ha}\left(X_{13}\right)$ & $0.182^{* *}$ & $0.327^{* *}$ & -0.042 \\
\hline Soil Porosity in $\%\left(X_{14}\right)$ & $0.299^{* *}$ & $0.252^{* *}$ & $0.327^{* *}$ \\
\hline Soil Manganese in $\mathrm{kg} / \mathrm{ha}\left(X_{15}\right)$ & $0.138^{*}$ & $0.211^{*}$ & -0.008 \\
\hline Soil Zinc in $\mathrm{kg} / \mathrm{ha}\left(X_{16}\right)$ & 0.033 & 0.095 & -0.051 \\
\hline Soil Copper in kg/ha $\left(X_{17}\right)$ & $0.212^{* *}$ & $0.215^{* *}$ & $0.213^{*}$ \\
\hline Soil Iron in $\mathrm{kg} / \mathrm{ha}\left(X_{18}\right)$ & 0.079 & 0.122 & 0.087 \\
\hline Soil Calcium in $\mathrm{kg} / \mathrm{ha}\left(X_{19}\right)$ & 0.054 & $0.196^{*}$ & -0.061 \\
\hline Soil Magnesium in $\mathrm{kg} / \mathrm{ha}\left(X_{20}\right)$ & $0.305^{* *}$ & $0.509^{* *}$ & 0.082 \\
\hline
\end{tabular}

** indicates significant correlation with coliform count at $5 \%$ level of significance.

* indicates significant correlation with coliform count at $1 \%$ level of significance.

Let us first examine the simple correlations between coliform count $Y$ and each of the explanatory variables $X_{1}, X_{2}, \ldots, X_{20}$ under study. Table (5) reveals that out of the 20 explanatory variables under study, 
11 exhibit significant simple correlations with the response variable. This justifies the use of multiple ordinal logistic regression models, however, it does not fix the explanatory variables to be included in the model. This is due to the fact that rather than the individual influence some of the variables may have joint influence on the response. We describe below the appropriate model selection and its features.

Ordinal Logistic Regression Models. Stepwise regression technique is used to develop the model for coliform count as it allows a free choice for each variable for inclusion or exit from the model depending on the corresponding influence. Out of the 20 explanatory variables 6 variables are selected in the case of well water sources and 5 variables are selected in the case of bore well water sources in the final model for the prediction of coliform count. The fitted model information is presented in Table (6) and Table (7) for well and bore well water sources respectively. Col.(1) of these two tables contains the 22 coliform categories and explanatory variables finally included in the model, col.(2) presents the corresponding estimated intercepts and regression coefficients and col. (3) their standard errors. Col. (4) provides the Wald test statistic, col.(5) and (6) the corresponding degrees of freedom and p-value testing the significance of each regression coefficient. Col (7) is the confidence interval for the estimates. Note that the stepwise regression method retains only those variables with significant regression coefficient (P-value $<0.05$ ), no matter whether the variables individually have significant correlation with the response or not. The last category 2400 is considered as the reference category. The parameters are estimated using method of maximum likelihood based on IRLS as described in section 2 .

Table 6

Ordinal Logistic Regression Model (Well)

\begin{tabular}{|c|c|c|c|c|c|c|c|c|}
\hline \multicolumn{2}{|c|}{ Variables } & \multicolumn{2}{|c|}{ Model Parameters } & \multirow[t]{2}{*}{ Std Error } & \multirow[t]{2}{*}{ Wald Test } & \multirow[t]{2}{*}{$\mathrm{df}$} & \multirow[t]{2}{*}{ P-Value } & \multirow[t]{2}{*}{$95 \%$ C.I } \\
\hline MPN Index & Category & Parameter & Estimate & & & & & \\
\hline 0 & 1 & $\alpha_{1}$ & -0.747 & 0.911 & 0.672 & 1 & 0.412 & $(-2.533,1.039)$ \\
\hline 3 & 2 & $\alpha_{2}$ & 0.397 & 0.809 & 0.241 & 1 & 0.624 & $(-1.189,1.983)$ \\
\hline 4 & 3 & $\alpha_{3}$ & 0.776 & 0.792 & 0.959 & 1 & 0.327 & $(-0.777,2.329)$ \\
\hline 7 & 4 & $\alpha_{4}$ & 1.606 & 0.773 & 4.311 & 1 & 0.038 & $(0.090,3.122)$ \\
\hline 9 & 5 & $\alpha_{5}$ & 1.606 & 0.773 & 4.311 & 1 & 0.038 & $(0.090,3.122)$ \\
\hline 10 & 6 & $\alpha_{6}$ & 1.885 & 0.771 & 5.974 & 1 & 0.015 & $(0.373,3.397)$ \\
\hline 14 & 7 & $\alpha_{7}$ & 1.885 & 0.771 & 5.974 & 1 & 0.015 & $(0.373,3.397)$ \\
\hline 15 & 8 & $\alpha_{8}$ & 2.007 & 0.771 & 6.781 & 1 & 0.009 & $(0.496,3.518)$ \\
\hline 20 & 9 & $\alpha_{9}$ & 2.226 & 0.771 & 8.338 & 1 & 0.004 & $(0.715,3.738)$ \\
\hline 21 & 10 & $\alpha_{10}$ & 3.230 & 0.784 & 16.975 & 1 & 0.000 & $(1.693,4.766)$ \\
\hline 23 & 11 & $\alpha_{11}$ & 3.609 & 0.793 & 20.736 & 1 & 0.000 & $(2.056,5.162)$ \\
\hline 28 & 12 & $\alpha_{12}$ & 3.706 & 0.795 & 21.726 & 1 & 0.000 & $(2.148,5.264)$ \\
\hline 39 & 13 & $\alpha_{13}$ & 3.753 & 0.796 & 22.214 & 1 & 0.000 & $(2.192,5.314)$ \\
\hline 43 & 14 & $\alpha_{14}$ & 3.987 & 0.803 & 24.650 & 1 & 0.000 & $(2.413,5.561)$ \\
\hline 75 & 15 & $\alpha_{15}$ & 4.876 & 0.835 & 34.057 & 1 & 0.000 & $(3.238,6.513)$ \\
\hline 120 & 16 & $\alpha_{16}$ & 5.311 & 0.854 & 38.647 & 1 & 0.000 & $(3.637,6.986)$ \\
\hline 150 & 17 & $\alpha_{17}$ & 5.382 & 0.858 & 39.387 & 1 & 0.000 & $(3.701,7.063)$ \\
\hline 210 & 18 & $\alpha_{18}$ & 5.529 & 0.865 & 40.900 & 1 & 0.000 & $(3.835,7.223)$ \\
\hline
\end{tabular}


Stochastic Modeling for Coliform Count Assessment in Ground Water

Table 6 to be continued

\begin{tabular}{lllllllll}
\hline 240 & 19 & $\alpha_{19}$ & 6.318 & 0.907 & 48.541 & 1 & 0.000 & $(4.541,8.095)$ \\
460 & 20 & $\alpha_{20}$ & 7.526 & 0.990 & 57.817 & 1 & 0.000 & $(5.586,9.465)$ \\
1100 & 21 & $\alpha_{21}$ & 9.618 & 1.191 & 65.191 & 1 & 0.000 & $(7.284,11.953)$ \\
$X_{1}$ & & $\beta_{1}$ & -0.003 & 0.001 & 5.970 & 1 & 0.015 & $(-0.005,-0.001)$ \\
$X_{4}$ & & $\beta_{4}$ & -0.036 & 0.015 & 5.771 & 1 & 0.016 & $(-0.066,-0.007)$ \\
$X_{5}$ & & $\beta_{5}$ & 0.103 & 0.028 & 13.553 & 1 & 0.000 & $(0.048,0.158)$ \\
$X_{6}$ & & $\beta_{6}$ & 0.702 & 0.133 & 28.010 & 1 & 0.000 & $(0.442,0.962)$ \\
$X_{10}$ & & $\beta_{10}$ & 0.756 & 0.123 & 38.034 & 1 & 0.000 & $(0.516,0.996)$ \\
$X_{14}$ & & $\beta_{14}$ & 0.054 & 0.019 & 7.577 & 1 & 0.006 & $(0.015,0.092)$ \\
\hline
\end{tabular}

Table 7

Ordinal Logistic Regression Model (Bore Well)

\begin{tabular}{|c|c|c|c|c|c|c|c|c|}
\hline \multicolumn{2}{|c|}{ Variables } & \multicolumn{2}{|c|}{ Model Parameters } & \multirow{2}{*}{ - Std Error } & \multirow{2}{*}{ Wald Test } & \multirow{2}{*}{$\mathrm{df}$} & \multirow{2}{*}{ P-Value } & \multirow{2}{*}{$95 \%$ C.I } \\
\hline MPN Index & Category & Parameter & Estimate & & & & & \\
\hline 0 & 1 & $\alpha_{1}$ & 3.129 & 1.160 & 7.281 & 1 & 0.007 & $(0.856,5.402)$ \\
\hline 3 & 2 & $\alpha_{2}$ & 3.894 & 1.171 & 11.064 & 1 & 0.001 & $(1.599,6.189)$ \\
\hline 4 & 3 & $\alpha_{3}$ & 4.915 & 1.197 & 16.866 & 1 & 0.000 & $(2.569,7.261)$ \\
\hline 7 & 4 & $\alpha_{4}$ & 5.677 & 1.223 & 21.539 & 1 & 0.000 & $(3.279,8.074)$ \\
\hline 9 & 5 & $\alpha_{5}$ & 6.109 & 1.241 & 24.221 & 1 & 0.000 & $(3.676,8.542)$ \\
\hline 10 & 6 & $\alpha_{6}$ & 6.109 & 1.241 & 24.221 & 1 & 0.000 & $(3.676,8.542)$ \\
\hline 14 & 7 & $\alpha_{7}$ & 6.239 & 1.247 & 25.019 & 1 & 0.000 & $(3.794,8.683)$ \\
\hline 15 & 8 & $\alpha_{8}$ & 6.511 & 1.261 & 26.662 & 1 & 0.000 & $(4.039,8.982)$ \\
\hline 20 & 9 & $\alpha_{9}$ & 6.511 & 1.261 & 26.662 & 1 & 0.000 & $(4.039,8.982)$ \\
\hline 21 & 10 & $\alpha_{10}$ & 7.664 & 1.340 & 32.716 & 1 & 0.000 & $(5.038,10.290)$ \\
\hline 23 & 11 & $\alpha_{11}$ & 8.430 & 1.412 & 35.664 & 1 & 0.000 & $(5.663,11.196)$ \\
\hline 28 & 12 & $\alpha_{12}$ & 8.430 & 1.412 & 35.664 & 1 & 0.000 & $(5.663,11.196)$ \\
\hline 39 & 13 & $\alpha_{13}$ & 8.430 & 1.412 & 35.664 & 1 & 0.000 & $(5.663,11.196)$ \\
\hline 43 & 14 & $\alpha_{14}$ & 8.761 & 1.447 & 36.673 & 1 & 0.000 & $(5.925,11.596)$ \\
\hline 75 & 15 & $\alpha_{15}$ & 10.249 & 1.633 & 39.395 & 1 & 0.000 & $(7.049,13.449)$ \\
\hline 120 & 16 & $\alpha_{16}$ & 10.686 & 1.688 & 40.092 & 1 & 0.000 & $(7.378,13.993)$ \\
\hline 150 & 17 & $\alpha_{17}$ & 11.217 & 1.760 & 40.644 & 1 & 0.000 & $(7.769,14.666)$ \\
\hline 210 & 18 & $\alpha_{18}$ & 11.217 & 1.760 & 40.644 & 1 & 0.000 & $(7.769,14.666)$ \\
\hline 240 & 19 & $\alpha_{19}$ & 12.425 & 1.941 & 40.979 & 1 & 0.000 & $(8.621,16.229)$ \\
\hline 460 & 20 & $\alpha_{20}$ & 15.779 & 2.309 & 46.708 & 1 & 0.000 & $(11.254,20.304)$ \\
\hline 1100 & 21 & $\alpha_{21}$ & 16.256 & 2.349 & 47.911 & 1 & 0.000 & $(11.653,20.860)$ \\
\hline$X_{1}$ & & $\beta_{1}$ & -0.005 & 0.002 & 10.437 & 1 & 0.001 & $(-0.009,-0.002)$ \\
\hline$X_{4}$ & & $\beta_{4}$ & -0.029 & 0.034 & 5.505 & 1 & 0.018 & $(-0.095,0.038)$ \\
\hline$X_{6}$ & & $\beta_{6}$ & 0.987 & 0.165 & 35.759 & 1 & 0.000 & $(0.663,1.310)$ \\
\hline$X_{10}$ & & $\beta_{10}$ & 0.709 & 0.164 & 18.614 & 1 & 0.000 & $(0.387,1.032)$ \\
\hline$X_{14}$ & & $\beta_{14}$ & 0.098 & 0.033 & 9.038 & 1 & 0.003 & $(0.034,0.162)$ \\
\hline
\end{tabular}


The ordinal logistic regression model for predicting coliform count in well water sources and bore well water sources are given in equations (9) and (10) respectively;

$$
\begin{aligned}
& \operatorname{prob}(D \leq k)=\frac{1}{1+e^{-\left(\alpha_{k}-\left(-0.003 X_{1}-0.036 X_{4}+0.103 X_{5}+0.702 X_{6}+0.756 X_{10}+0.054 X_{14}\right)\right)}} \\
& \operatorname{prob}(D \leq k)=\frac{1}{1+e^{-\left(\alpha_{k}-\left(-0.005 X_{1}-0.029 X_{4}+0.987 X_{6}+0.709 X_{10}+0.098 X_{14}\right)\right)}}
\end{aligned}
$$

where $k=1,2,3, \ldots, 21$.

By substituting the values of explanatory variables $\left(X_{p}\right)$ and estimates of intercepts ( $\left.\alpha_{k}\right)$ $(k=1,2,3, \ldots, 21 ; p=1,4,5,6,10$ and 14) from Table (6) in equations (5), (6) and (9) and from Table (7) in equations (5), (6) and (10) the cumulative probability and individual probabilities for each outcome for well and bore well water sources can be calculated. Since $D=22$ (MPN level 2400) is the reference category, the probability corresponding to the reference category can be calculated using the following equation

$$
\operatorname{prob}(D=22)=1-\sum_{k=1}^{21} \operatorname{prob}(D=k)
$$

The category with highest probability is then regarded as the probable coliform count. The overall significance of the model, goodness of fit of the model, accuracy measure and test for proportional odds are presented in Tables (8), (9), (10) and (11) respectively. Table (8) gives model fitting information, the null hypothesis in this test is that all of the regression coefficients in the model are equal to zero. Since the P-values for both wells and bore wells models are $<0.05$ we reject the null hypotheses and conclude that at least one of the regression coefficients in the models is not equal to zero. Goodness of fit of the models are tested in Table (9), the null hypothesis is model fit is good. The Pearson and Deviance statistics are intended to test whether the observed data are consistent with the fitted model. Since the P-Values are $>0.05$ we accept the null hypotheses and conclude that the models fit well for the data. Table (10) summarizes the proportion of variance in the response variable that can be accounted for by the explanatory variables. Table (11) tests the assumption of proportional odds, the null hypothesis tested being the explanatory variables have the same effect on the odds regardless of the categories. Since P-Values of the tests are $>0.05$ the proportional odds assumption is justified.

\begin{tabular}{|c|c|c|c|c|c|}
\hline Water Source & Model & -2 Log Likelihood & Chi-Square & $\mathrm{df}$ & P-Value \\
\hline \multirow{2}{*}{ Well } & Intercept Only & 777.64 & & & \\
\hline & Final & 612.12 & 165.52 & 6 & 0.00 \\
\hline \multirow{2}{*}{ Bore Well } & Intercept Only & 466.21 & & & \\
\hline & Final & 330.77 & 135.44 & 5 & 0.00 \\
\hline
\end{tabular}

Table 8

Model Fitting Information

Table 9

Goodness of Fit of the Fitted Model

\begin{tabular}{lllll}
\hline Water Source & Test & Chi-Square & df & P-Value \\
\hline Well & Pearson & 2046.31 & 2711 & 1.00
\end{tabular}


$\begin{array}{lll}\text { Deviance } & 612.12 & 2711\end{array}$

\begin{tabular}{lllll}
\hline Table 9 to be continued & & & \\
\hline \multirow{2}{*}{ Bore Well } & Pearson & 768.22 & 1627 & 1.00 \\
& Deviance & 330.77 & 1627 & 1.00 \\
\hline
\end{tabular}

Table 10

Pseudo R-Square

\begin{tabular}{llc}
\hline \multirow{2}{*}{ Test } & \multicolumn{2}{c}{ R-Square } \\
\cline { 2 - 3 } & Well & Bore Well \\
\hline Cox and Snell & 0.68 & 0.73 \\
Nagelkerke & 0.69 & 0.74 \\
\hline
\end{tabular}

Table 11

Test for Proportional Odds (Parallel Lines)

\begin{tabular}{|c|c|c|c|c|c|}
\hline Water Source & Model & -2 Log Likelihood & Chi-Square & df & P-Value \\
\hline \multirow{2}{*}{ Well } & Null Hypothesis & 612.12 & & & \\
\hline & General & 582.55 & 29.56 & 108 & 1.00 \\
\hline \multirow{2}{*}{ Bore Well } & Null Hypothesis & 330.77 & & & \\
\hline & General & 246.37 & 84.40 & 75 & 0.21 \\
\hline
\end{tabular}

Tables (12) and (13) present the illustration of model validation for well and bore well water sources respectively using $10 \%$ of the collected data. These tables indicate that 26 out of 30 predicted values agree exactly with the observed values, and inthe cases of disagreement the predicted values differ only by the next nearest level. Thus the models predict coliform count with an accuracy of about $87 \%$. Thus we have the stochastic regression models (9) and (10) capable of giving the level of coliform count present in the water that would be available in a well or bore well respectively in terms of the water source location characteristics.

Table 12

Model Validation (Well)

\begin{tabular}{lllllllll}
\hline S1. No $\begin{array}{l}\text { Distance of } \\
\text { water source } \\
\text { from nearest } \\
\text { stratum boundary }\end{array}$ & $\begin{array}{l}\text { Distance from } \\
\text { nearest septic }\end{array}$ & $\begin{array}{l}\text { Slope from } \\
\text { nearest Septic } \\
\text { tank in degrees }\end{array}$ & $\begin{array}{l}\text { Number of } \\
\text { septic tank nar } \\
\text { to the water } \\
\text { source }\end{array}$ & $\begin{array}{l}\text { Soil } \\
\text { Organic } \\
\text { Carbon }\end{array}$ & $\begin{array}{l}\text { Soil } \\
\text { Porosity }\end{array}$ & $\begin{array}{l}\text { Predicted } \\
\text { Coliform } \\
\text { Count }\end{array}$ & $\begin{array}{l}\text { Observed } \\
\text { Coliform } \\
\text { Count }\end{array}$ \\
\hline 1 & 5 & 10 & 1.6 & 10 & 1.09 & 43.04 & 2400 & 2400 \\
2 & 10 & 12 & 2.8 & 10 & 1.45 & 38.35 & 2400 & 2400 \\
3 & 15 & 10 & 3.8 & 8 & 2.08 & 42.41 & 2400 & 2400 \\
4 & 120 & 18 & 1.2 & 2 & 1.06 & 37.89 & 23 & 23 \\
5 & 130 & 10 & 46.8 & 2 & 1.78 & 36.70 & 2400 & 2400 \\
6 & 250 & 12 & 1.2 & 1 & 0.65 & 32.11 & 21 & 21 \\
7 & 300 & 15 & 0.56 & 1 & 1.54 & 36.73 & 21 & 23 \\
8 & 30 & 20 & 0.5 & 1 & 0.96 & 21.67 & 0 & 0 \\
9 & 30 & 11 & 1.2 & 1 & 0.06 & 54.87 & 15 & 15 \\
10 & 40 & 20 & 1.23 & 1 & 1.81 & 36.56 & 23 & 21 \\
11 & 27 & 7 & 1.69 & 3 & 1.23 & 43.49 & 460 & 460 \\
12 & 30 & 7 & 1.24 & 3 & 1.08 & 43.25 & 460 & 460 \\
13 & 20 & 10 & 1.25 & 1 & 1.94 & 50.69 & 240 & 210 \\
14 & 70 & 8 & 1.45 & 1 & 1.45 & 38.69 & 15 & 15 \\
\hline
\end{tabular}




\begin{tabular}{lllllllll}
\hline 15 & 50 & 8 & 1.45 & 8 & 2.90 & 45.37 & 2400 & 2400 \\
\hline
\end{tabular}

Table 13

Model Validation(Bore Well)

\begin{tabular}{llllllll}
\hline S1. No & $\begin{array}{l}\text { Distance of } \\
\text { water source } \\
\text { from nearest } \\
\text { stratum boundary }\end{array}$ & $\begin{array}{l}\text { Distance from } \\
\text { nearest septic }\end{array}$ & $\begin{array}{l}\text { Number of } \\
\text { septic tank near } \\
\text { to the water } \\
\text { source }\end{array}$ & Soil Porosity & $\begin{array}{l}\text { Soil Organic } \\
\text { Carbon }\end{array}$ & $\begin{array}{l}\text { Predicted } \\
\text { Coliform Count }\end{array}$ & $\begin{array}{l}\text { Observed } \\
\text { Coliform Count }\end{array}$ \\
\hline 1 & 200 & 20 & 2 & 38.87 & 0.35 & 4 & 4 \\
2 & 20 & 30 & 10 & 41.86 & 3.95 & 2400 & 460 \\
3 & 200 & 25 & 1 & 32.09 & 1.95 & 0 & 0 \\
4 & 20 & 20 & 5 & 32.49 & 2.5 & 75 & 75 \\
5 & 80 & 10 & 1 & 22.94 & 0.45 & 0 & 0 \\
6 & 80 & 20 & 1 & 26.27 & 1.3 & 0 & 0 \\
7 & 50 & 40 & 10 & 27.27 & 4.5 & 460 & 460 \\
8 & 100 & 20 & 1 & 41.79 & 1.26 & 4 & 4 \\
9 & 100 & 15 & 1 & 38.46 & 0.95 & 4 & 4 \\
10 & 90 & 20 & 1 & 37.57 & 1.45 & 4 & 4 \\
11 & 40 & 10 & 10 & 36.32 & 3.65 & 460 & 460 \\
12 & 250 & 10 & 1 & 30.53 & 0.95 & 0 & 0 \\
13 & 150 & 20 & 1 & 31.13 & 0.23 & 0 & 0 \\
14 & 250 & 20 & 1 & 36.10 & 0.85 & 0 & 0 \\
15 & 15 & 10 & 5 & 34.15 & 4.2 & 75 & 75 \\
\hline
\end{tabular}

\section{Model Application}

These models can be used in the following ways.

One straight forward use of the model is to estimate the quality of the water from the wells or bore wells prior to their construction in a location. This can be done by simply substituting the observed values of the location characteristics in the model(9) or (10) as the case may be. Another important use of the models is to decide the safest location in a compound to dig a well or bore well that ensures pure drinking water. For this first observe the minimum and maximum levels of each of the water source location characteristics. Regard the water source location characteristics in the model as variables taking values between the minimum and maximum levels. Compute the coliform count for each combination of the values of water source location characteristics varying from the minimum to maximum. From these results choose the location for which the coliform count is 0 . Usually the soil structure with in a compound may be homogeneous leaving the soil characteristics fixed, which reduces the number of computations. We have illustrated this procedure by performing computations for different combinations of values as given below.

$$
\begin{aligned}
& X_{1}: 10,50,100,200,500,1000 \\
& X_{4}: 5,10,20,50,100 \\
& X_{5}: 5,10,20,40,60,80 \\
& X_{6}: 1,2,3 \\
& X_{10}: 0.1,0.5,1,2,5 \\
& X_{14}: 20,25,30,40,50,60
\end{aligned}
$$

Out of the over 16000 different combinations of these values a few selected sets for which the coliform count is 0 are presented in Table (14). In the regression model (9) the variables $X_{1}$ and $X_{4}$ have negative 
coefficients so an increase in their values always results in smaller level of coliform count. Similarly in case of other variables having positive coefficients a decrease in their values always result in better water quality. Thus taking the values in Table (14) as reference and increasing $X_{1}, X_{4}$, and/or decreasing $X_{5}, X_{6}, X_{10}$, $X_{14}$ to the possible extent one can fix safer locations for digging wells in the compound.

Table 14

Coliform count Prediction (Well)

\begin{tabular}{|c|c|c|c|c|c|c|c|}
\hline S1. No & $\begin{array}{l}\text { Distance of } \\
\text { water source } \\
\text { from nearest } \\
\text { stratum } \\
\text { boundary in } \\
\text { meters }\end{array}$ & $\begin{array}{l}\text { Distance from } \\
\text { nearest septic } \\
\text { tank in meters }\end{array}$ & $\begin{array}{l}\text { Slope from } \\
\text { nearest Septic } \\
\text { tank in degrees }\end{array}$ & $\begin{array}{l}\text { Number of } \\
\text { septic tank near } \\
\text { to the water } \\
\text { source }\end{array}$ & $\begin{array}{l}\text { Soil Organic } \\
\text { Carbon }\end{array}$ & Soil Porosity & $\begin{array}{l}\text { Predicted } \\
\text { Coliform Count }\end{array}$ \\
\hline 1 & 1000 & 20 & 5 & 1 & 2 & 20 & 0 \\
\hline 2 & 10 & 100 & 5 & 1 & 2 & 20 & 0 \\
\hline 3 & 1000 & 50 & 10 & 1 & 2 & 20 & 0 \\
\hline 4 & 200 & 100 & 10 & 1 & 2 & 20 & 0 \\
\hline 5 & 1000 & 100 & 20 & 1 & 2 & 20 & 0 \\
\hline 6 & 1000 & 50 & 5 & 2 & 2 & 20 & 0 \\
\hline 7 & 500 & 100 & 5 & 2 & 2 & 20 & 0 \\
\hline 8 & 1000 & 50 & 10 & 2 & 2 & 20 & 0 \\
\hline 9 & 500 & 100 & 10 & 2 & 2 & 20 & 0 \\
\hline 10 & 1000 & 100 & 20 & 2 & 2 & 20 & 0 \\
\hline 11 & 500 & 100 & 5 & 3 & 2 & 20 & 0 \\
\hline 12 & 1000 & 100 & 10 & 3 & 2 & 20 & 0 \\
\hline 13 & 1000 & 100 & 20 & 3 & 2 & 20 & 0 \\
\hline 14 & 1000 & 50 & 5 & 1 & 2 & 30 & 0 \\
\hline 15 & 200 & 100 & 5 & 1 & 2 & 30 & 0 \\
\hline 16 & 1000 & 50 & 10 & 1 & 2 & 30 & 0 \\
\hline 17 & 500 & 100 & 10 & 1 & 2 & 30 & 0 \\
\hline 18 & 1000 & 100 & 20 & 1 & 2 & 30 & 0 \\
\hline 19 & 500 & 100 & 5 & 2 & 2 & 30 & 0 \\
\hline 20 & 1000 & 100 & 10 & 2 & 2 & 30 & 0 \\
\hline 21 & 1000 & 100 & 20 & 2 & 2 & 30 & 0 \\
\hline 22 & 1000 & 100 & 5 & 3 & 2 & 30 & 0 \\
\hline 23 & 1000 & 100 & 10 & 3 & 2 & 30 & 0 \\
\hline 24 & 1000 & 50 & 5 & 1 & 2 & 40 & 0 \\
\hline 25 & 500 & 100 & 5 & 1 & 2 & 40 & 0 \\
\hline 26 & 1000 & 100 & 10 & 1 & 2 & 40 & 0 \\
\hline 27 & 1000 & 100 & 20 & 1 & 2 & 40 & 0 \\
\hline 28 & 1000 & 100 & 5 & 2 & 2 & 40 & 0 \\
\hline 29 & 1000 & 100 & 10 & 2 & 2 & 40 & 0 \\
\hline 30 & 1000 & 100 & 5 & 3 & 2 & 40 & 0 \\
\hline 31 & 1000 & 100 & 10 & 3 & 2 & 40 & 0 \\
\hline 32 & 1000 & 100 & 5 & 1 & 2 & 50 & 0 \\
\hline 33 & 1000 & 100 & 10 & 1 & 2 & 50 & 0 \\
\hline 34 & 1000 & 100 & 5 & 2 & 2 & 50 & 0 \\
\hline 35 & 1000 & 100 & 10 & 2 & 2 & 50 & 0 \\
\hline 36 & 1000 & 100 & 5 & 3 & 2 & 50 & 0 \\
\hline 37 & 1000 & 100 & 5 & 1 & 2 & 60 & 0 \\
\hline 38 & 1000 & 100 & 10 & 1 & 2 & 60 & 0 \\
\hline
\end{tabular}




\begin{tabular}{llllllll}
\hline 39 & 1000 & 100 & 5 & 2 & 2 & 60 & 0 \\
\hline
\end{tabular}

\section{Conclusion}

This study is an attempt to model one of the most significant water quality characteristic; the coliform count level in MPN/100ml (which is an ordinal variable with 22 related categories) as a function of about 20 suspected water source location characteristics. We have arrived at two distinct models, one describing the coliform count level of well water in terms of 6 water source location characteristics, and the other in terms of 5 location characteristics relevant for water from bore wells. The rest of the variables are instrumental in deciding several other water quality characteristics which are also under our investigation. Though everybody believes that proximity of a water source location to waste dump areas or septic tanks may result in contamination of water, there were no scientific methods to fix the minimum safe distances. The significant feature of this study is that in addition to scientifically proving the dependence of the water quality on the distances from waste disposal area and septic tanks etc., it highlights the dependence of two other very significant soil characteristics, the soil organic carbon and soil porosity. Using the models one can estimate the quality of water that would be available in a location as well as determine the safest location for digging wells within a compound.

\section{Acknowledgement}

We are extremely thankful for the immense help of professors and laboratory staffs at Kerala Agricultural University Campus, Padannakkad for permitting and helping us to do the soil and water sample analysis in their laboratory.

\section{References}

[1]. Khurana, I. and Sen, R., Drinking Water Quality in Rural India: Issues and Approaches, www.wateraid.com, 2009.

[2]. Ramakrishnaiah C.R., Sadashivaiah,C., and Ranganna,G., Assessment of Water Quality Index for the Groundwater in Tumkur Taluk, Karnataka State, India, E-Journal of Chemistry, 2009, Vol.6, No.2, pp 523 - 530.

[3]. Kumar,N.V., Mathew, S. and Swaminathan, G., Multifactorial Fuzzy Approach for the Assessment of Groundwater Quality, J. Water Resource and Protection, 2010, pp 597-608.

[4]. Kumar, N. and Sinha, D.K., Drinking Water Quality Management Through Correlation Studies Among Various Physicochemical Parameters: A Case Study, International Journal of Environmental Sciences, 2010, Vol. 1, No. 2, pp 253-259.

[5]. Kumar,M., and Singh, Y., Interpretation of Water Quality Parameters for Villages of Sanganer Tehsil, by Using Multivariate Statistical Analysis, Water Resource and Protection, 2010, No. 2, pp 860-863.

[6]. Bandela, N. N. and Kosey, S. M., Mathematical Modelling for Water Quality of Nathsagar, International Journal of Research in Applied, Natural and Social Sciences, 2014, Vol. 2, No. 7, pp 107-112.

[7]. Karthick. B, Boominathan. M, Ali Sameer and Ramachandra, Spatial Assessment of Groundwater Quality in Kerala, India. The IUP Journal of Soil and Water Sciences, 2012 , Vol. 5, No. 1, pp 52-71.

[8]. Behera, B., Das, M., and Rana G. S., Studies on Ground Water Pollution Due to Iron Content and Water Quality in and Around, Jagdalpur, Bastar, district, Chattisgarh, India, Journal of Chemical and Pharmaceutical Research, 2012 , Vol.4, No. 8, pp 803-807.

[9]. Loucks, D. P. and van Beek, E., Water Resources Systems Planning and Management - An Introduction to Methods, Models and Applications, United Nations Educational, Scientific and Cultural Organization (UNESCO), 2005.

[10]. Mannina, G. and Viviani G., Parameter Uncertainty Analysis of Water Quality Model for Small River, 18th World IMACS / MODSIM Congress, Cairns, Australia , 2009, pp 13-17.

[11]. Pathak, H., 'Evaluation of Ground Water Quality Using Multiple Linear Regression and Mathematical Equation Modeling',Analele Universitatii din Oradea Seria Geografie, 2012 , pp 304 - 307.

[12]. Mustapha, A. and Abdu, A., Application of Principal Component Analysis \& Multiple Regression Models in Surface Water 
Quality Assessment, Journal of Environment and Earth Science, 2012, Vol 2, No.2 , pp 16-23.

[13]. Fannin, T.E., Parker, M. and Maret, T.J., Multiple Regression Analysis for Evaluating Non-Point Source Contributions to the Water Quality in Green River, Wyoming, R.R Johnson editor, 1985 , pp - 201 -205.

[14]. Hynds, D.P., Misstear, D.B., Gill, W.L., Development of a Microbial Contamination Susceptibility Model for Private Domestic Groundwater Sources, Water Resources Research , 2012, Vol. 48, No. 12.

[15]. Heydari, M.M., Abasi, A. and Rohani, S.M., Correlation Study and Regression Analysis of Drinking Water Quality in Kashan City, Iran, Middle-East Journal of Scientific Research, 2013 , Vol. 13, No. 9, pp 1238-1244.

[16]. Bain, R., Cronk, R., Hossain, R., Sophie Bonjour, S., Onda, K., Wright, J., Yang, H., Slaymaker, T., Hunter, P., Pruss-Ustun, A. and Bartram, J., Global Assessment of Exposure to Fecal Contamination Through Drinking Water Based on a Systematic Review, Tropical Medicine and International Health, 2014 , Vol. 19 No. 8, pp 917-927.

[17]. Yule, G.U, Kendall, M.G., An Introduction to the Theory of Statistics, C. Griffin and company limited, London, 1922.

[18]. Koutsoyiannis. A, Theory of Econometrics, (Second Edition), Palgrave, UK, 1973.

[19]. Draper, N.R. and Smith, H., Applied Regression Analysis, Wiley, NY, 1966.

[20]. Hosmer, D.W., and Lemeshow S., Applied Logistic Regression, Wiley-Interscience, US, 2000.

[21]. Kleinbaum, D.G., Klein, M., Logistic Regression - A Self-Learning Text, Springer, 2002.

[22]. Montgomery, D.C., Peck, E.A., and Vining, G.G., Introduction to Linear Regression Analysis, 2003. (Third Edition), Wiley Series 